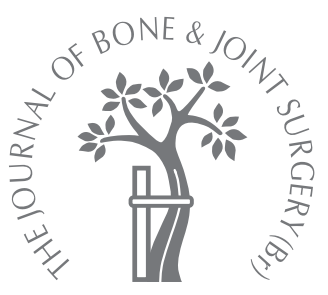

L. Savarino,

D. Tigani,

M. Greco,

N. Baldini,

A. Giunti

From the Rizzoli

Orthopaedic

Institute, Bologna, Italy

\footnotetext{
= L. Savarino, BSc, Researcher

M. Greco, Technician

Laboratory for Orthopaedic

Pathophysiology and

Regenerative Medicine

Istituto Ortopedico Rizzoli, Via

di Barbiano 1/10, 40136

Bologna, Italy.

D. Tigani, MD, Orthopaedic Surgeon

N. Baldini, MD, Professor

A. Giunti, MD, Professor

Orthopaedic and Traumatology

Department I

Rizzoli Orthopaedic Instiute, via

Pupilli 1, 40136 Bologna, Italy.

Correspondence should be sent to Dr L. Savarino; e-mail:

lucia.savarino@ior.it
}

(ㄷ)2010 British Editorial Society of Bone and Joint Surgery doi:10.1302/0301-620X.92B5 $23452 \$ 2.00$

$J$ Bone Joint Surg [Br] 2010;92-B:634-8.

Received 21 September 2009;

Accepted after revision 15

January 2010

\section{The potential role of metal ion release as a marker of loosening in patients with total knee replacement}

\author{
A COHORT STUDY
}

We investigated the role of ion release in the assessment of fixation of the implant after total knee replacement and hypothesised that ion monitoring could be a useful parameter in the diagnosis of prosthetic loosening. We enrolled 59 patients with unilateral procedures and measured their serum aluminium, titanium, chromium and cobalt ion levels, blinded to the clinical and radiological outcome which was considered to be the reference standard. The cut-off levels for detection of the ions were obtained by measuring the levels in 41 healthy blood donors who had no implants. Based on the clinical and radiological evaluation the patients were divided into two groups with either stable $(n=24)$ or loosened ( $\mathbf{n}=35$ ) implants.

A significant increase in the mean level of $\mathrm{Cr}$ ions was seen in the group with failed implants $(p=0.001)$. The diagnostic accuracy was $71 \%$ providing strong evidence of failure when the level of $\mathrm{Cr}$ ions exceeded the cut-off value. The possibility of distinguishing loosening from other causes of failure was demonstrated by the higher diagnostic accuracy of $\mathbf{8 3} \%$, when considering only patients with failure attributable to loosening.

Measurement of the serum level of $\mathrm{Cr}$ ions may be of value for detecting failure due to loosening when the diagnosis is in doubt. The other metal ions studies did not have any diagnostic value.

The number of total knee replacements (TKR) presenting for revision continues to increase. ${ }^{1-3}$ For successful revision the cause of failure should be understood. This is currently established by clinical and radiological examination. Aseptic loosening is the main problem, with periprosthetic bone loss being the principal factor limiting the survival of the implant. Osteolysis results from a particle-induced foreign-body response to wear of the implant and corrosion. The metal surfaces may be subject to wear and corrosion, with particle and ion release, which may be involved in the process of failure. A bacterial presence may also contribute to the degradation of the implant and enhance the inflammatory process. ${ }^{4}$

The relationship between the systemic concentration of metal ions and failure in TKR has received little attention. Some reports have shown that failure in TKR is associated with elevated ion levels, ${ }^{5-8}$ but the diagnostic use of these data has not been described.

We hypothesised that serum ions could be surrogate markers in the diagnosis of loosening in TKR. To explore this we measured the serum concentrations of aluminium (Al), titanium (Ti), chromium (Cr) and cobalt $(\mathrm{Co})$ in patients with unilateral TKR. The clinical and radiological course was used for reference and the diagnostic accuracy of the tests was evaluated.

\section{Patients and Methods}

The Institutional Ethics Committee on human research approved the design of the study. A pre-test power calculation was performed in order to define the sample size. For an effect size, one SD from the control previously analysed in a pilot study was used because a biologically or clinically meaningful difference in outcome was not known. This represented $2.3 \mathrm{mg}$ for $\mathrm{Al}, 0.72 \mathrm{mg}$ for $\mathrm{Ti}, 0.15 \mathrm{mg}$ for $\mathrm{Cr}$ and $0.14 \mathrm{mg}$ for Co. We found that $90 \%$ power for all the elements corresponded to a sample size of 22 subjects for each group, with statistical significance level of $\mathrm{p}<0.05$.

The study included 69 patients with TKR admitted for a programme of pain management. A personal history was obtained from each patient, including details of other potential sources of metal ion release. Thus, ten patients with hip or contralateral implants were excluded. Ingestion of drugs containing metal ions, and renal impairment were also exclusion criteria, but no patient had these 
characteristics. Accordingly, 59 patients with unilateral TKRs were enrolled and underwent blood sampling. A clinical and radiological evaluation was performed by an orthopaedic surgeon (DT) and radiologist independently of one another and was applied as the reference for the diagnosis of failure. Using the classification of Baré, MacDonald and Bourne ${ }^{9}$ the patients were divided into two groups comprising 24 with stable (group I) and 35 with failed loose implants (group II). The laboratory staff were blinded as to which group the patients had been allocated.

All the patients were assessed by the Knee Society clinical rating system ${ }^{10}$ which gives a total knee score depending on pain, range of movement and stability, and a function score based on walking and stair-climbing ability. Although in hip replacement the level of activity has not been considered to be a confounding factor, ${ }^{11}$ we obtained a score for the level of activity following a method described previously. ${ }^{12}$ The radiological analysis was made on anteroposterior, lateral and skyline views according to the method of Ewald. ${ }^{13} \mathrm{~A}$ change in position or subsidence of the implant as seen on sequential radiographs also indicated loosening, as well as progressive widening of the cement-bone or bone-prosthesis interface and fragmentation of the cement under a component. ${ }^{14}$ An algorithm, described in a previous paper, was used to diagnose septic loosening pre-operatively. ${ }^{15}$

Group-I patients had a good clinical outcome with the ability to walk for more than $3 \mathrm{~km}$ per day and no radiological evidence of failure. After testing, they were followed for at least two years and did not show any sign of loosening. Group II patients had undergone revision for septic and aseptic loosening, infection, rotational malalignment, patellofemoral problems or instability. ${ }^{9,16,17}$ The groups were matched for age, gender and duration of follow-up. Those patients with malalignment or instability without loosening had symptoms from the early post-operative period and those with loosening had symptoms from six months post-operatively to a few years from surgery.

The implants had either Co-based alloy for the femoral and tibial components $(\mathrm{n}=22)$ or a Co-based femoral component and a TiA1V alloy tibial component $(\mathrm{n}=37)$ (Table I).

A group of 41 normal volunteers (group III, blood donors), who in the last three months had not taken any medication and had not received any metal implants were recruited in a pilot study in order to obtain cut-off values for each ion.

lon measurement. All testing procedures were validated according to the quality assurance standard (EN ISO 9001). ${ }^{18}$ Blood samples were obtained from the antecubital vein of fasting patients, collected in metal-free Vacutainers (Becton Dickinson and Co, Meyland, France) and coded so that the examiner did not know the source of the sample. In order to avoid contamination from the needle, the first $5 \mathrm{ml}$ of blood withdrawn were discarded. Serum was separated by centrifugation at $400 \mathrm{~g}$ for ten minutes at $4^{\circ} \mathrm{C}$.

The ion content was measured using a graphite furnace atomic absorption spectrometer (GFAAS) equipped with
Table I. Details of the patients with stable TKRs (group I) and failed implants (group II)

\begin{tabular}{lll}
\hline & Group I & Group II \\
\cline { 2 - 3 } Parameter & (n= 24) & (n = 35) \\
\hline $\begin{array}{l}\text { Gender } \\
\quad \text { Male }\end{array}$ & 5 & 9 \\
$\quad$ Female & 19 & 26 \\
Mean age in years (range) & 69 (59 to 84) & 67 (47 to 79) \\
Alloy & & \\
$\quad$ CoCrMo & 7 & 15 \\
$\quad$ TiA1V + CoCrMo & 17 & 20 \\
& & \\
Indication for primary surgery & & \\
$\quad$ Osteoarthritis & 23 & - \\
$\quad$ Rheumatoid arthritis & 1 & 1 \\
$\quad$ Post-traumatic arthritis & - & \\
Indication for revision surgery & & 11 \\
$\quad$ Septic loosening & & 2 \\
$\quad$ Aseptic loosening & & 3 \\
$\quad$ Infection & - & 1 \\
$\quad$ Rotational malalignment & & 30 (8 to 74) \\
$\quad$ Patellofemoral problems & & \\
$\quad$ Instability & & \\
$\quad$ Mean follow-up in months (range) & 39 (10 to 108) & \\
\hline
\end{tabular}

double-background correction deuterium/Zeeman (Unicam Model Solaar 939 QZ; Unicam, Cambridge, United Kingdom) after calibration using certified standard solutions for each element. The furnace thermal programs and spectrometer parameters have been reported previously. ${ }^{19-21}$ The specimens were diluted with 0.1 vol $\% \mathrm{HNO}_{3}$ and 0.05 vol\% Triton X100 and analysed as $15 \mu \mathrm{l}$ aliquots in triplicate. For analysis of $\mathrm{Cr}$ and $\mathrm{Co}$ magnesium nitrate was added as a matrix modifier. All the results were expressed as $\mathrm{ng} / \mathrm{ml}$, equivalent to $\mu \mathrm{g} / \mathrm{l}$ and parts per billion. The sensitivity of the method was established by using detection limits for the sample matrix, which were $1.36 \mathrm{ng} / \mathrm{ml}$ for $\mathrm{Al}$, $2.91 \mathrm{ng} / \mathrm{ml}$ for Ti, $0.06 \mathrm{ng} / \mathrm{ml}$ for $\mathrm{Cr}$ and $0.08 \mathrm{ng} / \mathrm{ml}$ for Co. All ion levels which were below the detection limit were assigned the detection level values. The accuracy and precision of the methods were validated using SRM 1598 NIST (National Institute of standards and technology, standard reference program, Gaithesburg, Maryland) human serum for all the elements and trace elements UTAK (UTAK Laboratories Inc, Valencia, California) for Cr. Results with a related deviation standard $\%$ greater than $10 \%$ were rejected to ensure repeatability of the test.

Statistical analysis. Quantitative results were expressed as the mean and range and the median value. Specific differences between groups were evaluated by the MannWhitney $U$ test to compare one continuous and one nominal variable or Fisher's exact test to compare two nominal variables. 
Table II. Serum ion levels ( $\mathrm{ng} / \mathrm{ml}$ ) expressed as the mean (range) in both groups

\begin{tabular}{lllll}
\hline & Group I & Group II & Control & p-value \\
\hline $\mathrm{Al}$ & $3.30(1.36$ to 7.95$)$ & $4.34(1.55$ to 8.99$)$ & $3.98(1.36$ to 8.22$)$ & 0.14 \\
$\mathrm{Ti}$ & $2.91(2.91$ to 3.73$)$ & $3.05(2.91$ to 6.43$)$ & $3.20(2.91$ to 5.4$)$ & 0.991 \\
$\mathrm{Cr}$ & $0.24(0.06$ to 1.39$)$ & $0.45(0.06$ to 1.44$)$ & $0.24(0.06$ to 0.50$)$ & 0.001 \\
$\mathrm{Co}$ & $0.44(0.08$ to 4.65$)$ & $1.10(0.08$ to 8.80$)$ & $0.26(0.08$ to 0.59$)$ & 0.75 \\
\hline
\end{tabular}

Table III. A comparison of the ion levels between all failed implants (Group II) and those failed implants with loosening to assess the performance of $\mathrm{Cr}$ ion levels in detecting loosening

\begin{tabular}{lll}
\hline & Implants with failure & Implants with loosening \\
\hline Mean (SEM) Cohen's kappa & $0.446(0.15)$ & $0.653(0.15)$ \\
Pearson chi-squared value & 9.1 & 15.31 \\
Fisher's exact p-value & 0.0022 & 0.0004 \\
& & \\
Diagnostic performance (95\% confidence interval) & & $0.74(0.54$ to 0.93$)$ \\
$\quad$ Sensitivity & $0.56(0.37$ to 0.74$)$ & $0.91(0.79$ to 1.03$)$ \\
$\quad$ Specificity & $0.91(0.79$ to 1.03$)$ & $0.83(0.71$ to 1.04$)$ \\
$\quad$ Diagnostic accuracy & $0.71(0.59$ to 0.84$)$ & $0.88(0.71$ to 1.04$)$ \\
$\quad$ Positive predictive value & $0.88(0.73$ to 1.04$)$ & $8.11(6.76$ to 9.45$)$ \\
$\quad$ Likelihood ratio test + & $6.11(4.75$ to 7.47$)$ & $0.80(0.64$ to 0.96$)$ \\
$\quad$ Negative predictive value & $0.52(0.09$ to 0.94$)$ & $0.29(-0.47$ to 1.05$)$ \\
$\quad$ Likelihood ratio test - & $0.49(0.05$ to 0.94$)$ & \\
\hline
\end{tabular}

The area-under-receiver-operating characteristic (ROC) curve (AUC) measure was used as the predictivity model. The $75^{\text {th }}$ percentile of ion values measured in the pilot study were chosen as the cut-off value and Cohen's kappa ${ }^{22}$ was used to evaluate the agreement between cut-offs and failure. The relation between the results and diagnostic grouping was described according to the Standards for Reporting of Diagnostic Accuracy ${ }^{23}$ using probabilistic measures such as sensitivity, specificity, likelihood ratios and predictive values. ${ }^{24}$ A likelihood ratio positive test above 10 and a likelihood ratio negative test below 0.1 have been noted as providing convincing diagnostic evidence, whereas those above 5.0 and below 0.2 give good diagnostic evidence. ${ }^{25}$ Multivariate logistic regression analysis, considering cutoff, age, gender, follow-up, activity level, type of fixation and bearing, was undertaken to find the best model for predicting failure. The correlation between ion values and follow-up and age was calculated using the Spearman rho correlation test. The data were analysed using SPSS software version 15.0 (SPSS Inc, Chicago, Illinois).

\section{Results}

Patients with failed implants (group II) showed a significant increase in the mean Cr level, in comparison with the control group (Mann-Whitney U test, $\mathrm{p}=0.03$ ) and those with stable implants (group I, Table II). By contrast, group I did not show any significant difference in their mean $\mathrm{Cr}$ levels compared with the control group (Mann-Whitney U test, $\mathrm{p}=0.55)$. Logistic regression applying $\mathrm{Cr}$ cut-off, age, follow-up, gender, activity level, type of fixation and type of bearing showed the evaluation of $\mathrm{Cr}$ to be the best model for predicting failure (odds ratio 9.5; 1.27 to $70.9795 \%$
CI; Mann-Whitney U test, $\mathrm{p}=0.028$ ). In addition, the ROC curve showed that measurement of $\mathrm{Cr}$ was a good predictivity marker (AUC 0.78; 0.63 to $0.8895 \%$ CI; MannWhitney $U$ test $p<0.0001)$. In order to establish the diagnostic accuracy of testing of the Cr level to predict failure, the $75^{\text {th }}$ percentile of the mean ion concentration in control subjects of $0.35 \mathrm{ng} / \mathrm{ml}$ was designated as the upper reference limit (cut-off). Cohen's kappa showed the agreement between cut-off and failure with a mean of 0.446 and SEM of 0.15 (Mann-Whitney $U$ test, $p=0.008$ ). The differences between the clinical outcome of success or failure of the TKR and the value of ion analysis in predicting failure were evaluated using Fisher's exact test (Table III).

A significant correlation was found between the $\mathrm{Cr}$ and Co values $(r=0.50$; Spearman's rho, $p=0.009)$ in patients with a failed TKR, whereas there was no correlation between ion levels and follow-up and between ion levels and age $(\mathrm{Al}$ age $\mathrm{R}=0.14, \mathrm{p}=0.49 ; \mathrm{Ti}$ age $\mathrm{R}=0.01$, $\mathrm{p}=0.94$; Cr age $\mathrm{R}=0.08, \mathrm{p}=0.68$; Co age $\mathrm{R}=0.11$, $\mathrm{p}=0.55)$ (Al follow-up $\mathrm{R}=0.50, \mathrm{p}=0.99$; Ti follow-up $\mathrm{R}=0.46, \mathrm{p}=0.25$, Cr follow-up $\mathrm{R}=0.018$; Co follow-up $\mathrm{R}=0.20, \mathrm{p}=0.55$.

A further analysis was undertaken excluding implants which had failed because of rotational misalignment, instability, patellofemoral problems or sepsis without loosening. After the exclusions, no differences were found between patients with failure because of septic or aseptic loosening (Mann-Whitney $U$ test, $\mathrm{p}=0.46$ ), concerning $\mathrm{Cr}$ and they were therefore analysed together. Cohen's kappa and the diagnostic accuracy were recalculated in order to evaluate the ability of Cr levels to predict failure exclusively due to loosening. A better diagnostic accuracy was demonstrated 
to distinguish patients with loosening from patients with other mechanisms of failure (Table III).

$\mathrm{Ti}, \mathrm{Al}$ and Co concentrations did not show a significant variation between groups and were not further analysed $($ Ti $\mathrm{p}=0.95$, Al $\mathrm{p}=0.89$, Co $\mathrm{p}=0.75)$.

\section{Discussion}

A differential diagnosis should be obtained first when planning revision TKR. ${ }^{16}$ Generally, this can be established by clinical and radiological assessment, but sometimes the cause is not apparent. Supplementary investigations may be of value. The estimation of the serum level of cross-linked $\mathrm{N}$-terminal telopeptide and osteoprotegerin has been proposed as surrogate markers, ${ }^{26-28}$ but these indices have not shown good diagnostic accuracy.

We hypothesised that the serum ion concentrations would be a good surrogate marker for diagnosing a malfunctioning TKR and that such monitoring could contribute to the differential diagnosis of loosening. There have been a few reports which have shown an increase in $\mathrm{Ti}$ release in patients with failure of metal-backed patellar components. ${ }^{6-8,29-31}$ Dissemination of metal ions to synovial tissue, lymph nodes, liver and spleen in failed implants has been described. ${ }^{32-34}$ Luetzner et $\mathrm{al}^{35}$ studied the levels of serum Co, Cr, and molybdenum by GFAAS, but only in patients with stable unconstrained TKRs, and demonstrated, differently from us, an increase in ion levels in comparison with control patients without implants. Liu et $\mathrm{al}^{5}$ evaluated ion values by GFAAS in two groups of patients with failed and stable cementless TKR, but the measurements were performed on whole blood. Nevertheless, they found that the level of $\mathrm{Cr}$ ions was significantly increased in patients with loosened implants in comparison with those with stable TKRs. This suggested that there was an association between an increase in the ion level and failure. Sarmiento-González et $\mathrm{al}^{36}$ used InductivelyCoupled Plasma Mass Spectrometry for ion determination in whole blood of patients with TKR, but did not find any significant difference between those with stable implants and healthy subjects. However, the diagnostic accuracy of this method has not been assessed.

We preferred graphite furnace atomic absorption spectrometer to ICP-MS because although the latter is advantageous for multi-element analysis, we were measuring only a few and the sample volume required was much smaller for GFAAS than for Inductively-Coupled Plasma Mass Spectrometry. Additionally, GFAAS uses simpler and less costly instrumentation. ${ }^{37}$

A limitation of our study was that we did not consider the ion content of red blood cells since there has been some evience that $\mathrm{Cr}$ accumulates in these cells. However, the literature is divided on this topic. ${ }^{38,39}$ We followed the recommendations of MacDonald, Brodner and Jacobs ${ }^{40}$ in relation to hips and measured ion levels in the serum.

Concentrations lower than the cut-off were associated with stable implants, except in two cases, and a clinico- radiologically stable condition was still present at followup at two years. By contrast, high levels of $\mathrm{Cr}$ were detected in patients with failure. A high specificity and positive predictive value for $\mathrm{Cr}$ ion levels confirmed that this measurement gave good diagnostic evidence for loosening. In regard to the implants included in our study, multivariate analysis showed that neither the type of fixation nor the type of bearing was correlated with the outcome of the prosthesis and levels of $\mathrm{Cr}$ ions. When failure was not due to loosening, the $\mathrm{Cr}$ ion level was not increased whereas in most implants with septic and aseptic loosening an increase in the $\mathrm{Cr}$ ion level occurred. This supports our hypothesis that the test could be used to distinguish loosening from other mechanisms of failure when the radiological signs remain in doubt. Values for Co levels did not show any significant differences between groups. ${ }^{37}$ This could be dependent on the kinetics associated with the Co ions which are transported from the site of the implant and eliminated in the urine, whereas $\mathrm{Cr}$ ions are stored in the tissues and slowly excreted. ${ }^{41}$ However, the significant correlation between $\mathrm{Cr}$ and Co concentrations in patients with failed implants showed also that Co had a tendency to increase, but when considered alone this was not statistically significant. Concentrations of $\mathrm{Al}$ ions did not appear to be relevant probably because of the low proportion within the alloy. Evaluation of $\mathrm{Ti}$ was probably underestimated because of the high instrumental detection limit.

In conclusion, measurement of the level of $\mathrm{Cr}$ ions appeared to be a good surrogate marker of loosening whereas that of other metal ions did not show significant changes. When the clinical and radiological signs are unclear estimation of the serum Cr level could be of value.

\footnotetext{
We thank Dr V. Bochicchio for his contribution to the patient enrolment.

No benefits in any form have been received or will be received from a commercial party related directly or indirectly to the subject of this article.
}

\section{References}

1. Kane RL, Saleh KJ, Wilt TJ, et al. Total knee replacement. Evid Rep Technol Assess (Summ) 2003;86:1-8.

2. Baumann C, Rat AC, Osnowycz G, et al. Do clinical presentation and pre-operative quality of life predict satisfaction with care after total hip or knee replacement? J Bone Joint Surg [Br] 2006;88-B:366-73.

3. Ethgen $\mathbf{0}$, Bruyère $\mathbf{0}$, Richy $\mathbf{F}$, Dardennes $\mathbf{C}$, Reginster JY. Health-related quality of life in total hip and total knee arthroplasty: a qualitative and systematic review of the literature. J Bone Joint Surg [Am] 2004;86-A:963-74.

4. Beech IB, Sunner JA, Hiraoka K. Microbe-surface interactions in biofouling and biocorrosion processes. Int Microbiol 2005;8:157-68.

5. Liu TK, Liu SH, Chang CH, Yang RS. Concentration of metal elements in the blood and urine in the patients with cementless total knee arthroplasty. Tohoku $\mathrm{J}$ Exp Med 1998;185:253-62.

6. von Schroeder HP, Smith DC, Gross AE, et al. Titanemia from total knee arthroplasty: a case resulting from a failed patellar component. J Arthroplasty 1996;11:620-5.

7. Jacobs JJ, Silverton C, Hallab NJ, et al. Metal release and excretion from cementless titanium alloy total knee replacements. Clin Orthop 1999;358:173-80.

8. Stulberg BN, Merritt K, Bauer TW. Metallic wear debris in metal-backed patellar failure. J Biomed Mater Res B Appl Biomater 1994;5:9-16.

9. Baré J, MacDonald SJ, Bourne RB. Preoperative evaluations in revision total knee arthroplasty. Clin Orthop 2006;446:40-4

10. No authors listed. The Knee Society rating system. http://www.kneesociety.org/ web/outcomes.html. (date last accessed 22 March 2010). 
11. Heisel C, Silva M, Skipor AK, Jacobs JJ, Schmalzried TP. The relationship between activity and ions in patients with metal-on-metal bearing hip prostheses. $J$ Bone Joint Surg [Am] 2005;87-A:781-7.

12. Devane PA, Horne JG, Martin K, Coldham G, Krause B. Three-dimensional polyethylene wear of a press-fit titanium prosthesis: factors influencing generation of polyethylene debris. J Arthroplasty 1997;12:256-66.

13. Ewald FC. The Knee Society total knee arthroplasty roentgenographic evaluation and scoring system. Clin Orthop 1989;248:9-12.

14. Schenk MM, Dalinka MK. Radiographic evaluation of the painful total knee replacement. In: Lotke PA, Garino JP, eds. Revision total knee arthroplasty. Philadelphia, PA: Lippincott-Raven, 1999:355-70.

15. Savarino L, Tigani D, Baldini N, Bochicchio V, Giunti A. Pre-operative diagnosis of infection in total knee arthroplasty: an algorithm. Knee Surg Sports Traumatol Arthrosc 2009;17:667-75.

16. Garino JP, Lotke PA. Failure related to axial and rotational malalignment. In: Lotke PA, Garino JP, eds. Revision total knee arthroplasty. Philadelphia, PA: LippincottRaven, 1999:67-76.

17. Vince KG. Why knees fail. J Arthroplasty 2003;18(Suppl 1):39-44.

18. No authors listed. ISO 9001: Quality management systems - requirements. European Committee for standardisation. Brussels; CEN, 2008. http://www.iso.org.150/ 150_catalogue. (date last accessed 22 March 2010).

19. Savarino L, Granchi D, Ciapetti G, et al. Ion release in stable hip arthroplasties using metal-on-metal articulating surfaces: a comparison between short- and medium-term results. J Biomed Mater Res A 2003;66:450-6.

20. Savarino L, Granchi D, Ciapetti G, et al. Ion release in patients with metal-onmetal hip bearings in total joint replacement: a comparison with metal-on-polyethylene bearings. J Biomed Mater Res 2002;63:467-74.

21. Savarino L, Greco M, Cenni $\mathbf{E}$, et al. Differences in ion release after ceramic-onceramic and metal-on-metal total hip replacement: medium-term follow-up. J Bone Joint Surg [Br] 2006;88-B:472-6.

22. Cohen J. A coefficient of agreement for nomincal scales. Educ Psychol Meas 1960;20:37-46.

23. Deeks JJ. Systematic reviews in health care: systematic reviews of evaluations of diagnostic and screening tests. BMJ 2001;323:157-62.

24. Bossuyt PM, Reitsma JB, Bruns DE, et al; Standards for Reporting of Diagnostic Accuracy. Towards complete and accurate reporting of studies of diagnostic accuracy: the STARD initiative. BMJ 2003;326:41-4.

25. Trenti T. Evidence-based laboratory medicine as a tool for continuous professional improvement. Clin Chim Acta 2003;333:155-67.

26. Granchi D, Pellacani A, Spina M, et al. Serum levels of osteoprotegerin and receptor activator of nuclear factor-kappaB ligand as markers of periprosthetic osteolysis. J Bone Joint Surg [Am] 2006;88-A:1501-9.
27. Li MG, Thorsen K, Nilsson KG. Increased bone turnover as reflected by biochemical markers in patients with potentially unstable fixation of the tibial component. Arch Orthop Trauma Surg 2004;124:404-9.

28. Savarino L, Granchi D, Cenni E, et al. Systemic cross-linked N-terminal telopeptide and procollagen I C-terminal extension peptide as markers of bone turnover after total hip arthroplasty. J Bone Joint Surg [Br] 2005;87-B:571-6.

29. Leopold SS, Berger RA, Patterson L, et al. Serum titanium level for diagnosis of a failed, metal-backed patellar component. J Arthroplasty 2000;15:938-43.

30. Sunderman FW Jr, Hopfer SM, Swift T, et al. Cobalt, chromium, and nickel concentrations in body fluids of patients with porous-coated knee or hip prostheses. $J$ Orthop Res 1989:7:307-15.

31. Takai S, Yoshino N, Kusaka Y, Watanabe Y, Hirasawa Y. Dissemination of metals from a failed patellar component made of titanium-base alloy. J Arthroplasty 2003;18:931-5.

32. Ichinose S, Muneta T, Sekiya I, et al. The study of metal ion release and cytotoxicity in Co-Cr-Mo and Ti-Al-V alloy in total knee prosthesis - scanning electron microscopic observation. J Mater Sci Mater Med 2003;14:79-86.

33. La Budde JK, Orosz JF, Bonfiglio TA, Pellegrini VD Jr. Particulate titanium and cobalt-chrome metallic debris in failed total knee arthroplasty: a quantitative histologic analysis. J Arthroplasty 1994:9:291-304.

34. Urban RM, Jacobs JJ, Tomlinson MJ, et al. Dissemination of wear particles to the liver, spleen, and abdominal lymph nodes of patients with hip or knee replacement. J Bone Joint Surg [Am]2000;82-A:457-76.

35. Luetzner J, Krummenauer F, Lengel AM, Ziegler J, Witzleb WC. Serum meta ion exposure after total knee arthroplasty. Clin Orthop 2007;461:136-42.

36. Sarmiento-González A, Marchante-Gayón JM, Tejerina-Lobo JM, Paz-Jiménez J, Sanz-Medel A. High-resolution ICP-MS determination of $\mathrm{Ti}, \mathrm{V}, \mathrm{Cr}, \mathrm{Co}, \mathrm{Ni}$, and Mo in human blood and urine of patients implanted with a hip or knee prosthesis. Anal Bioanal Chem 2008;391:2583-9.

37. Bolann BJ, Rahil-Khazen R, Henriksen H, Isrenn R, Ulvik RJ. Evaluation of methods for trace-element determination with emphasis on their usability in the clinical routine laboratory. Scand J Clin Lab Invest 2007;67:353-66.

38. Walter LR, Marel E, Harbury R, Wearne J. Distribution of chromium and cobalt ions in various blood fractions after resurfacing hip arthroplasty. J Arthroplasty 2008;23:814-21.

39. Afolaranmi GA, Tettey JN, Murray HM, Meek RM, Grant MH. The effect of anticoagulants on the distribution of chromium $\mathrm{VI}$ in blood fractions relevance to patients with metal orthopedic implants. J Arthroplasty 2008;25:118-20.

40. MacDonald SJ, Brodner W, Jacobs JJ. A consensus paper on metal ions in metal-on-metal hip arthroplasties. J Arthroplasty 2004;19(Suppl 3):12-6.

41. Merritt K, Brown SA. Distribution of cobalt chromium wear and corrosion products and biologic reactions. Clin Orthop 1996;329(Suppl):233-43. 